\title{
Use of algae scenedesmus as bioindicators of water pollution from active ingredients
}

\begin{abstract}
Public health is greatly influenced worldwide by the appearance of bacteria resistant to the active ingredients of drugs that should eradicate them. This natural process today is speeded up due to the incorrect introduction into rivers and aquifers of drugs or of their constituents. Hence continuous monitoring of surface of water pollution is required. The method of using bioindicators has limited management costs and can be applied in diversified territories. Bioindicators can assess environmental state, provide an early warning signal of its changes, diagnose the cause of an environmental problem. The algae have all the features necessary to carry out these tasks.

In this study, Scenedesmus microalgae were contacted with four common active pharmaceutical ingredients Ofloxacin, Cloxacillin, Chloramphenicol and Propranolol. The stress in the case of this indicating biosystem is represented by the damage suffered by the two different activities of algae: breathing performed in the dark and photosynthesizing performed in the light. With a simulation system of both the situations, and through measurements of the redox potential, we observed the stress that microalgae suffer when they are contacted with the active ingredients. The results show that algae behave as an efficient biomonitoring system of the explored pollution.
\end{abstract}

Keywords: active ingredients, algae scenedesmus, biondicators, MDR, redox potential, water pollution
Volume 6 Issue 5 - 2017

\author{
Dell Aglio E, Francesco Cosentino, Luigi \\ Campanella \\ Department of Chemistry, La Sapienza University of Rome, Italy
}

Correspondence: Emanuele Dell?Aglio, Department of Chemistry, La Sapienza University of Rome, P.le.Aldo Moro 5, Rome 00185, Italy, Tel 3292227083,

Email emanuele.dell.aglio@gmail.com Received: December 07, 2017 | Published: December 29,
2017
Abbreviations: MDR, multi drug-resistant; $\mathrm{LD}_{50}$, lethal dose 50

\section{Introduction}

Water is one of the essential sources for the life of every living being, but today it is increasingly compromised because of pollution due to the introduction of harmful substances produced by anthropic activities $^{1}$ into rivers and aquifers. Among these harmful substances drugs are also included. Proper drug treatment requires that they must be disposed of in a special containers in pharmacies, as their active ingredients and excipients make them able to modify the ecosystem..$^{2}$ In addition to their illicit domestic disposal ${ }^{3}$ and to illicit drug use ${ }^{4}$ the partial treatment of waste water both indoor from the pharmaceutical industries ${ }^{5}$ and outdoor from the sewage treatment plants can be mentioned, containing metabolized and not metabolized molecules excrete (urine, stools). ${ }^{6}$ The active ingredients in sewage, if not removed or destroyed, flow into rivers and lakes where they can persist for a long time, being accumulated and influencing flora ${ }^{7}$ and fauna, ${ }^{8}$ including humans. ${ }^{9}$

The presence of drug residues is among the worst concerns of world public health ${ }^{10}$ because through a selection process they lead to the appearance of drug-resistant bacteria that should kill them MDRs (multidrug-resistant). Travelers are often colonized by MDR bacteria, which can so easily be transported and transmitted. ${ }^{11}$ Although the appearance of antimicrobial resistance is a natural phenomenon, its development and spread are accelerated by the improper use of drugs. Another advantage of biomonitoring is related to its ability to give information about the integral toxicity of an item as deriving from different sources. It is therefore necessary to monitor the water to assess the presence of these foreign compounds.

By the term biomonitoring it is meant the monitoring of pollution by living organisms. We can investigate the variations that bio indicating organisms suffer in presence of toxics, ${ }^{12}$ obtaining estimates of the toxic effects on living matter, with limited management costs and easily covering vast areas and diverse territories. Bioindicators on which the research is focusing are microalgae ${ }^{13}$ and among these those of the genus Scenedesmus, ${ }^{14,15}$ which allow to highlight the synergistic effects of several sources of stress and how these alter the abundance and the health state of a biological community in a water environment. Stress can cause the algal structure a functional perturbation, highlighted by a different production of metabolites.

The most involved biochemical metabolisms are breathing and photosynthesis, the first produces $\mathrm{CO} 2$ and consumes $\mathrm{O} 2$, while the latter has the opposite behavior. When breathing and photosynthesis are disturbed by the presence of a toxic substance, the normal concentration of one of the two products is dampened or exacerbated depending on whether and which one of the two metabolic processes is inhibited or activated.

\section{Materials and methods}

\section{Algae cultivation}

The cultures of the micro-algae of the genus Scenedesmus were carried out in mineral water Saguaro, specially chosen because it contained the main feeding species Table 1, in amounts suitable for the proliferation and survival of the algae. The culture vessel is equipped with an aquarium aerator, Newair Aquarium Systems, which allows a homogeneous stirring of the entire solution; while the light source is a sunlight lamp.

\section{Experimental equipment}

As it can be seen in Figure 1,200mL of algal aqueous solution are contained in a $250 \mathrm{~mL}$ beaker, closed with Parafilm. Throughout the duration of the experiment, the solution is magnetically stirred at a speed of $250 \mathrm{rpm}$ sufficient to keep the algae well in suspension. The 
Osram Ultra Vitalux lamp, ${ }^{11}$ which simulates sunlight, is connected to a digital timer programmed to alternate current supply, subjecting the micro-algae to cycles in which the lamp is turned on, and off alternatively every $5 \mathrm{~min}$.

Table I Saguaro water analysis carried out by the Department of Agriculture of Federico II University of Naples on 09/0I/2013

\begin{tabular}{ll}
\hline Source Temperature & $14.3^{\circ} \mathrm{C}$ \\
\hline Electrical conductivity at $20^{\circ} \mathrm{C}$ & $919 \mu \mathrm{S} / \mathrm{cm}$ \\
$\mathrm{pH}$ at $18^{\circ} \mathrm{C}$ & 7.26 \\
\hline & Concentration $(\mathbf{m g} / \mathbf{L})$ \\
\hline Fixed residue at $18^{\circ} \mathrm{C}$ & 409 \\
Calcium $\mathrm{Ca}^{2+}$ & 77 \\
Magnesium $\mathrm{Mg}^{2+}$ & 11.4 \\
Sodium $\mathrm{Na}^{+}$ & 35 \\
Potassium $\mathrm{K}^{+}$ & 1.7 \\
Bicarbonates $\mathrm{HCO}^{3-}$ & 342 \\
Sulfates $\mathrm{SO}^{4-}$ & 13.8 \\
Nitrate $\mathrm{NO}^{3-}$ & 0.45 \\
Chlorides $\mathrm{Cl}^{-}$ & 27 \\
Silica SiO2- & 15.4 \\
\hline
\end{tabular}

The instrumentation shown in Figure 1 is enclosed in a chamber Figure 2, consisting of plywood walls held together by wooden boards, to the right of which there is a black plastic window. The room prevents the outside light from penetrating inside and reaching the algae solution. The reference calomel electrode and the working electrode, a platinum plate, are connected to the Microprocessor $\mathrm{pH}$ meter model 223 of Hanna Instruments, which in turn is connected via a serial cable to a PC, where the HI 92000 software receives and records the redox potential values read by the instrument every minute for 120 minutes. $\mathrm{pH}$ was monitored by a glass electrode and the temperature of the solution monitored by a Hanna instruments portable thermometer.

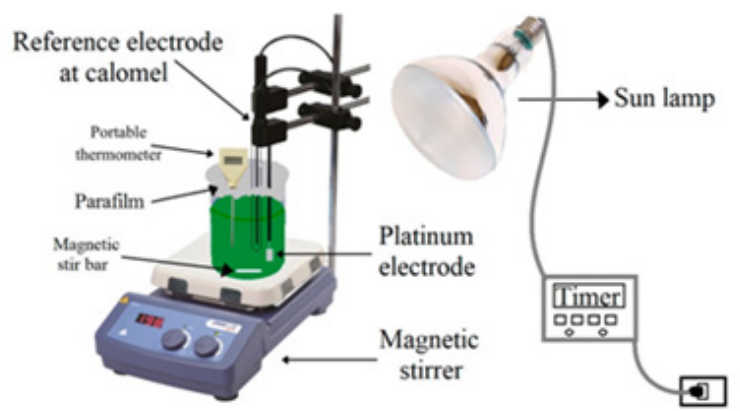

Figure I Schematic arrangement of the components inside the chamber representing the experimental system.

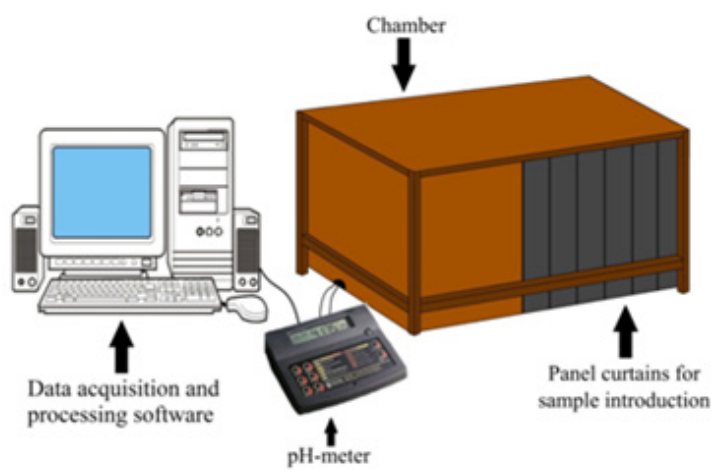

Figure 2 Monitoring and recording equipment.

\section{Chemicals}

The active ingredients used, listed in Table 2, are all manufactured by Sigma-Aldrich. For each one, 50mg were taken and dissolved in $100 \mathrm{~mL}$ of distilled water. The active ingredients in the solution were added to the beaker containing microalgae, 20minutes before the beginning of the data acquisition, by means of a $20 \mathrm{~mL}$ BD Plastipak syringe puncturing the Parafilm. Two experimental series were performed, in the first being injected $20 \mathrm{~mL}$ of the active ingredient solution and in the second $40 \mathrm{~mL}$, to see how the increased amount of the active ingredient influenced the photosynthesis and respiration of the algae. Each experiment was carried out in triplicates the curves present in the next paragraph are obtained from the mean values.

${ }^{1}$ Nominal wattage $300 \mathrm{~W}$, nominal voltage $230 \mathrm{~V}$, diameter $127 \mathrm{~mm}$, length $185 \mathrm{~mm}$, lifespan $1000 \mathrm{~h}$, base E27.

\section{Results and discussion}

The two metabolic processes of the algae, photosynthesis and respiration, should produce and respectively consume a stoichiometric amount of $\mathrm{O}_{2}$ and $\mathrm{CO}_{2}$, so their alternated values should be constant unless there is a stop or a decrease of one or both the two processes. During the photosynthetic process, the redox potential curve increases, $\mathrm{O}_{2}$ is produced and $\mathrm{CO}_{2}$ consumed, while breathing has the opposite behaviour. The trend of redox potential of the algal solution Figure 3, decreases, with a slope of -0.205 , over time meaning that algae consume more $\mathrm{O}_{2}$ than they can produce. The standard deviation increases with the increase of the experiment time, excluding the first 15 minutes in which the electrode goes to equilibrium in the algal solution, it passes from a minimum of $4.6 \mathrm{mV}$ to a maximum of $15.2 \mathrm{mV}$. Being a biological system, algae due to unknown factors can respond differently so repetitions are unavoidable. Table 3 shows the average values with the relative standard deviations of all the redox potential curves. Because of the high quantity of values in Table 3 are only reported those ones at intervals of 5 minutes, that is the alternation time of switching on and off the lamp.

The $\mathrm{pH}$ value slowly increases by 0.8 , shifting to a more basic value. The temperature of the solution increases of up $2^{\circ} \mathrm{C}$, due to the heat emitted by the lamp. Although in the Nernst equation there is the term of temperature, in our case it has not been considered due to the slight variation during the experiments.

\section{Ofloxacin}

Figure 4 shows the trends of redox potential and of $\mathrm{pH}$ for the experiments with Ofloxacin. For the 20 and $40 \mathrm{~mL}$ solutions of Ofloxacin the minimum and maximum standard deviations are 7.2, 10.8 and $0.39,16.09 \mathrm{mV}$ respectively. Because of these values the trend is placed in the same range of redox potentials in the case of solutions containing only algae (blank), so to understand the effect of the active principle it is necessary to study the trend of the shape more close of its values. Peaks, compared to the algal solution, are jagged and the slope increases with the increase of the amount of toxic solution. A sudden increase in the redox potential to the addition of the active ingredient is observed. The $40 \mathrm{~mL}$ addition jump signal is twice high as that one of $20 \mathrm{~mL}$ Ofloxacin containing solution. At the same time there is a slight and rapid decrease of $\mathrm{pH}(0.14)$. Although initially the photosynthesis appears to be activated by pollutant, the decrease of the redox potential compared to that one of the only algal solution (Figure 3 ) is more rapid and is due to a greater activation of the metabolism of respiration or to the inhibition of the photosynthetic process. 
Table 2 Characteristics of active ingredients and solutions

\begin{tabular}{|c|c|c|c|c|c|}
\hline Active Ingredient & Purity (\%) & $\begin{array}{l}\text { Molar Mass } \\
(\mathrm{g} / \mathrm{mol})\end{array}$ & $\begin{array}{l}\text { Solubility } \\
\text { (mg/mL) }\end{array}$ & Hazard Statements & $\begin{array}{l}\text { Molarity of } \\
\text { Experimental Solution }\end{array}$ \\
\hline Ofloxacin & Not available & 361.37 & 28.3 & $\mathrm{H} 303$ & $1.38 \cdot 10-3$ \\
\hline Cloxacillin Sodium salt monohydrate & 397 & 475.88 & 50 & H3।5-H3।7-H319-H334-H335 & $1.05 \cdot 10-3$ \\
\hline Propranolol hydrochloride & ${ }^{3} 98$ & 295.8 & 50 & $\mathrm{H} 302$ & $1.69 \cdot 10-3$ \\
\hline
\end{tabular}

Table 3 List of average values with the relative standard deviations of all the redox potential curves at intervals of 5 minutes, that is the alternation time of switching on and off the lamp

\begin{tabular}{|c|c|c|c|c|c|c|c|c|c|c|c|c|c|c|c|c|c|c|}
\hline \multirow{3}{*}{$\frac{\text { Time (min) }}{5}$} & \multicolumn{2}{|l|}{$\begin{array}{l}\text { Algal } \\
\text { Solution }\end{array}$} & \multicolumn{2}{|c|}{$\begin{array}{l}\text { Ofloxacin } \\
(20 \mathrm{~mL})\end{array}$} & \multicolumn{2}{|c|}{$\begin{array}{l}\text { Ofloxacin } \\
(40 \mathrm{~mL})\end{array}$} & \multicolumn{2}{|c|}{$\begin{array}{l}\text { Cloxacillin } \\
(20 \mathrm{~mL})\end{array}$} & \multicolumn{2}{|c|}{$\begin{array}{l}\text { Cloxacillin } \\
\text { (40 mL) }\end{array}$} & \multicolumn{2}{|c|}{$\begin{array}{l}\text { Chloramphenicol } \\
(20 \mathrm{~mL})\end{array}$} & \multicolumn{2}{|c|}{$\begin{array}{l}\text { Chloramphenicol } \\
(40 \mathrm{~mL})\end{array}$} & \multicolumn{2}{|c|}{$\begin{array}{l}\text { Propranolol } \\
(20 \mathrm{~mL})\end{array}$} & \multicolumn{2}{|c|}{$\begin{array}{l}\text { Propranolol } \\
(40 \mathrm{~mL})\end{array}$} \\
\hline & Average & SD & Average & SD & Average & SD & Average & SD & Average & SD & Average & SD & Average & SD & Average & SD & Average & SD \\
\hline & 174.9 & & 173.2 & 7.8 & 175.3 & 0.8 & I78.2 & 8.3 & I77.I & I.I & 173 & 3 & 173 & 2.7 & $17 \mid .2$ & 12.5 & 183.1 & 7.5 \\
\hline 10 & 181.5 & 5.2 & I78.I & 7.4 & 178 & 3.2 & 181.6 & 7.5 & 182.1 & 3.3 & 178.9 & 4.3 & 181.5 & 2.7 & 181.4 & 20.7 & 7187.6 & 7.6 \\
\hline 15 & I77.I & 4.4 & 174.7 & 7.3 & 171.8 & 7.3 & 178.8 & 8 & 178.4 & 5.6 & 176 & 3.8 & 181.3 & 2.7 & 182.2 & 27.2 & 2 184.4 & 8 \\
\hline 20 & 182.2 & 2.8 & 175.6 & 8.9 & 175.6 & 6.3 & 180.2 & 8 & I 79.7 & 3.8 & I79.| & 4.2 & 183.3 & 3.2 & 186.3 & 29.8 & 3187.8 & 4.4 \\
\hline 25 & 176.7 & 3.7 & 177.7 & 8.7 & 183.4 & 16.1 & 172.7 & 7.3 & 173.6 & 7.1 & 159.2 & 5 & 150.9 & 3.3 & 182.1 & 38.3 & 174.6 & 4.7 \\
\hline 30 & 180 & 4 & 175.5 & 9.6 & 178.8 & 14.4 & 173.2 & 7.8 & 175.5 & 9.7 & 152 & 9.3 & 133.8 & 2.9 & 177.3 & 34.4 & 4168.1 & 4.3 \\
\hline 35 & 174.3 & 4.8 & 169.3 & 9.7 & 172.5 & 14.1 & 169.4 & 8.1 & 170 & 10.8 & 139.6 & 8.9 & 113.6 & 3.1 & 161.9 & 34.3 & 150.9 & 1.2 \\
\hline 40 & 177 & 5.7 & 169.2 & 9.8 & 170.6 & 13 & 170.4 & 7.5 & 171.3 & 11.3 & 137 & 9.9 & 113.6 & 3.2 & 149 & 33.8 & 3129.9 & 7.3 \\
\hline 45 & 172.6 & 6.8 & I64.I & 9.9 & 163.6 & 13 & 166.1 & 8 & 165 & 12.7 & 126 & 9.5 & 97.8 & 4.9 & 137 & 33.7 & 7121.5 & 1.2 \\
\hline 50 & 174.8 & 7.9 & 163.9 & 9.8 & 162.4 & 11.5 & 166.4 & 7.6 & 166 & 13.6 & 124.4 & 9.8 & 101.2 & 3.4 & 128.5 & 33.7 & 7113.8 & 0.5 \\
\hline 55 & I70.I & 8.3 & I 58.7 & 10.3 & I57.1 & 10.6 & 161.8 & 8.8 & 160.8 & 14.1 & II4.7 & 9.1 & 88.9 & 5.6 & 119.9 & 31.1 & 104.6 & 0.4 \\
\hline 60 & 172.2 & 9.5 & I59.1 & 10.2 & 156.3 & 8.8 & 162.6 & 7.9 & 161.6 & 14.7 & 113.9 & 10.1 & 92.7 & 4 & 109.3 & 29.5 & 591 & 0.5 \\
\hline 65 & 167.5 & 9.8 & 154.4 & 10.4 & 151.4 & 7.2 & 158.8 & 8.8 & 156.9 & 14.3 & 104.8 & 9.1 & 83.8 & 5.9 & 103.7 & 26.2 & 87.6 & 0.4 \\
\hline 70 & 169.4 & II & I 55.7 & 10.5 & 151.9 & 4.8 & 159.5 & 8.2 & I57.7 & 15.5 & 104.3 & 9.6 & 86.1 & 4.1 & 96.1 & 26.8 & 378.1 & 1.9 \\
\hline 75 & 164.9 & II & 150.8 & 10.7 & 146 & 5.6 & 155.3 & 8.7 & 153.6 & 17 & 95.4 & 8.5 & 79.1 & 5.2 & 93.2 & 22.6 & 79.7 & 1.5 \\
\hline 80 & 166.6 & 12 & 151.8 & 10.6 & 147.4 & 3.7 & I56.I & 8.2 & 154.2 & 18 & 94.4 & 9.5 & 80.2 & 3.3 & 86.4 & 21.4 & 744.4 & 1.5 \\
\hline 85 & 162.6 & 11.9 & | 48.7 & 9.8 & 142.1 & 3.7 & 151.8 & 9.1 & 150 & 17.6 & 86.7 & 9 & 74 & 4 & 84.2 & 16 & 77.2 & 1.8 \\
\hline 90 & 164.2 & 12.8 & 149.6 & 9.6 & I 44.4 & 2.1 & 152.5 & 8.8 & 150 & 18.1 & 87.1 & 9.3 & 73 & 3 & 77.2 & 11.5 & 74 & 3.5 \\
\hline 95 & 160.4 & 12.8 & I 46.7 & 9.1 & 139.5 & 2.1 & | 48.7 & 9.6 & 147.6 & 19.7 & 79.1 & 9.1 & 68.1 & 3.1 & 77.4 & 8.6 & 73.3 & 4 \\
\hline 100 & 161.9 & 13.6 & 148.2 & 9.2 & 140.9 & 1.4 & 148.9 & 8.9 & |48.| & 20.4 & 78.3 & 9.6 & 66.4 & 2.7 & 70 & 1.4 & 69.7 & 5.5 \\
\hline 105 & 158.4 & 13.7 & 145.9 & 7.2 & 136.7 & 0.7 & 145.5 & 9.3 & 144.7 & 20.2 & 71.2 & 9.1 & 62.5 & 2.7 & 70.5 & 2.4 & 69.7 & 7 \\
\hline 110 & 159.7 & 14.5 & I47.I & 7.2 & 137.6 & 2.7 & 146 & 9.1 & 146.8 & 21.5 & 70.5 & 9 & 60.2 & 2.7 & 67.6 & 3.8 & 68.2 & 4. I \\
\hline 115 & 156.6 & 14.5 & 143.7 & 7.3 & I34.I & 1.7 & 142.7 & 10.1 & 143.6 & 21.3 & 64.6 & 8.3 & 56.5 & 2.7 & 68.7 & 6 & 70.8 & 5.2 \\
\hline 120 & 157.7 & 15.2 & 145.2 & 8.2 & 134.9 & 2.8 & 142.9 & 9.4 & 144.3 & 22 & 63.3 & 8.6 & 53.6 & 2.7 & 67.7 & 7.1 & 68.3 & 4.9 \\
\hline
\end{tabular}

Table 4 Degree of toxicity of the active ingredients tested

\begin{tabular}{lll} 
Active Ingredient Name & Degree of Toxicity & LD50 Value \\
\hline Propranolol & 10 & $565 \mathrm{mg} / \mathrm{kg}$ \\
Chloramphenicol & 2.3 & $2500 \mathrm{mg} / \mathrm{kg}$ \\
Cloxacillin & 1.1 & $5000 \mathrm{mg} / \mathrm{kg}$ \\
Ofloxacin & 1 & $5450 \mathrm{mg} / \mathrm{kg}$ \\
\hline
\end{tabular}

The difference between the blank and the presence of Ofloxacin is also confirmed by the slope of the two curves, -0.3346 for the $20 \mathrm{~mL}$ and -0.4455 for the $40 \mathrm{~mL}$. The slope increases negatively compared to that one of blank; this indicates that the active ingredient disturbs the algal system and the effect is greater as the concentration of the principle increases.

\section{Cloxacillin}

Figure 5 shows the trends of redox potential and $\mathrm{pH}$ of the experiments with Cloxacillin. The $20 \mathrm{~mL}$ curve has the standard deviations, min 7.2 and max 10.9, practically identical to those ones of the Ofloxacin. On the other hand, as it regards the $40 \mathrm{~mL}$ solution, as for the blank, the standard deviation increases from 5.6 to $22.2 \mathrm{mV}$ with the increase of the experiment time. Because of the standard deviation values, in this case, it is not possible to distinguish between the two curves at different concentrations of active principle or between these ones and the blank.
While the slope distinguishes the blank curve from those ones with the active ingredient, indicating disturbance of the algal system, it does not distinguish between the two curves in which the Cloxacillin is present, because the values are not significantly different, -0.3424 $(20 \mathrm{ml})$ and $-0.3476(40 \mathrm{ml})$. It is concluded that it is not possible to determine with certainty whether the addition of Cloxacillin, although harmful to human health, may disturb the metabolic pathways of microalgae because the trend is very similar to that one of the algal solution.

\section{Chloramphenicol}

For the 20 and $40 \mathrm{~mL}$ Chloramphenicol solutions the minimum and maximum standard deviations are 2.7, 10.1 and 2.6, $6.4 \mathrm{mV}$ respectively. The redox potential values of the two solutions differ from the blank. Figure 6 shows the trends after the addition of Chloramphenicol which, as it can be seen, has a net potential fall at the addition of the active ingredient, indicating a strong inhibition of 
the photosynthetic process, halving the amount of dissolved oxygen in water in a short time. The addition of $40 \mathrm{~mL}$ results in a decrease of about $20 \mathrm{mV}$ higher than the signal obtained by the addition of $20 \mathrm{~mL}$. More important seems the peak performance in the case of $40 \mathrm{~mL}$ addition, over time the peaks flatten, indicating a progressive abatement of both metabolic functions. Moreover the slopes of the two curves are $-1.0737(20 \mathrm{Ml})$ and $-1.339(40 \mathrm{~mL})$, indicating the high effect of Chloramphenicol presence on microalgae. $\mathrm{pH}$, as in the previous cases, does not undergo substantial variations.

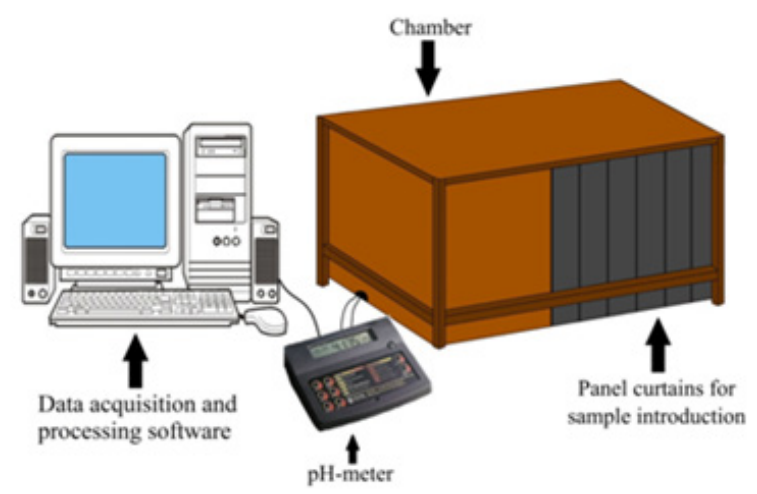

Figure 3 Redox potential and $\mathrm{pH}$ curves of algal solution.

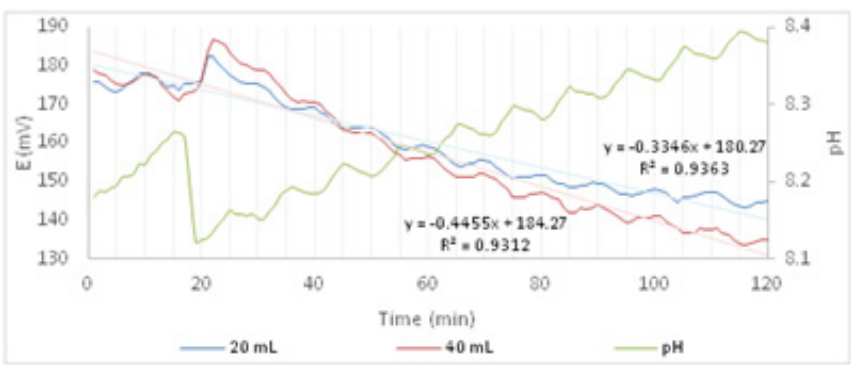

Figure 4 Redox potential and $\mathrm{pH}$ curves of the algal solution after the addition of a solution containing Ofloxacin.

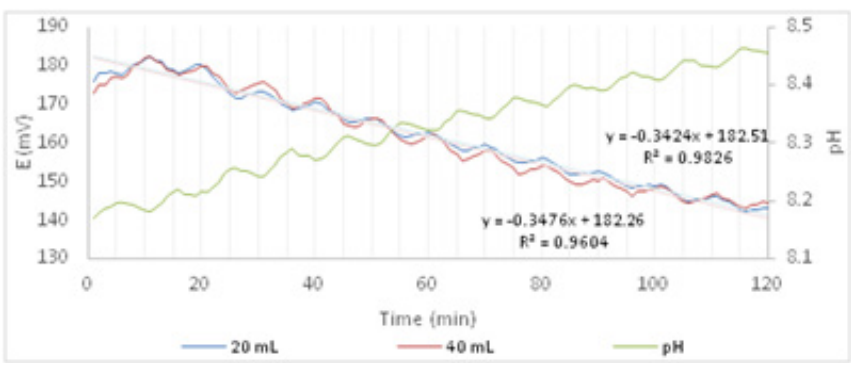

Figure 5 Redox potential and $\mathrm{pH}$ curves of the algal solution after the addition of a solution containing Cloxacillin.

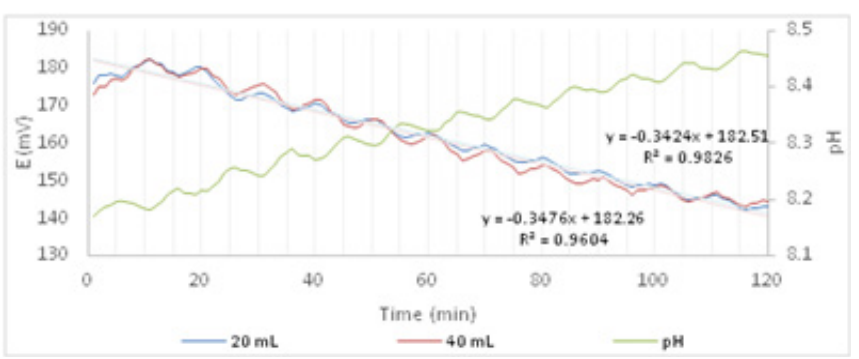

Figure 6 Redox potential and $\mathrm{pH}$ curves of the algal solution after the addition of a solution containing Chloramphenicol.

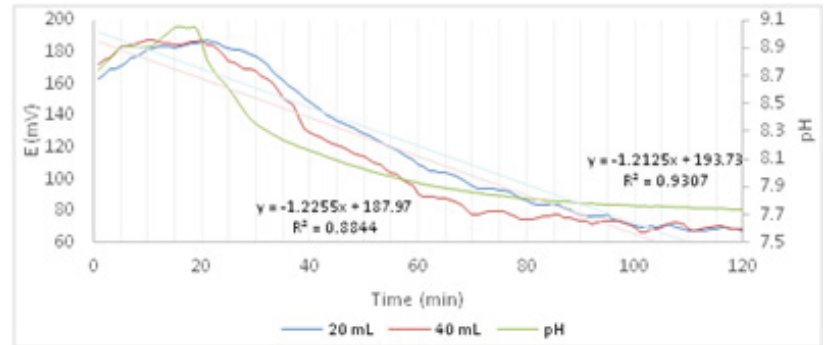

Figure 7 Redox potential and $\mathrm{pH}$ curves of the algal solution after the addition of a solution containing Propranolol.

\section{Propranolol}

As for the latter active principle, as can be seen in Figure 7, there is a remarkable decrease of the redox potential, mainly due to the Chlorohydrate composition which results in a $\mathrm{pH}$ variation of 1.2. Since the fall of the potential is altered by this $\mathrm{pH}$ variation, it is difficult to determine which one of the two metabolic processes has been inhibited, but about the use of microalgae as bioindicators, we can still state that the introduction of this active principle causes an appreciable change of their behaviour. The standard deviation of the solution at $20 \mathrm{~mL}$ since the $20^{\text {th }}$ minute decreases with increasing time, passing from a max of 38.5 to a min of 1.2 , while for the $40 \mathrm{~mL}$ solution the min is 0.4 and the max 8.6. These standard deviations, compared to other trends, are anomalous due to the stress that suddenly the algal system undergoes.

The effect of Propranolol is emphasized by the slope of the curves, $-1.2125(20 \mathrm{~mL})$ and $-1.2255(40 \mathrm{~mL})$. Since very similar values it is not possible to discriminate between the two curves. Stabilizing $\mathrm{pH}$ also stabilizes the redox potential trends, but metabolic activities are compromised. The maximum harmful effect is already observed by introducing only $20 \mathrm{~mL}$ of the active ingredient solution. The four tested active ingredients produce on the algal cells a shift of the redox potential to lower values. The same trend is observed by working with microalgae alone. This demonstrates that in our measuring system the photosynthetic activity and the respiratory activity are not equivalently supported. The active ingredients don't always alter the gradient and the values of the potential reached at the end of the experiment, but the slope is always altered. The variations of the latter ones correspond to the toxic action of the active principles against photosynthesis and breathing, the slopes inform us about the ability of the algal system to react to the toxic action that contrasts the natural process. In the case of the proposed 4 active substances, Propranolol produces the most pronounced toxic effect, both in the value of slope and in the significant decrease of redox potential. Qualitatively similar behaviour, but less accentuated by slope, is shown by Chloramphenicol. In the case of the other two active ingredients, the slope has been limited, and the curves, in presence and absence of the tested principle, are very similar, indicative of a low toxicity.

\section{Validation of toxicity biomonitoring}

The active ingredients tested are subdivided into two groups: the first consisting of Chloramphenicol and Propranolol (the most toxic), and the second one of Ofloxacin and Cloxacillin (less toxic). The results obtained by reading the redox potential agree with the $\mathrm{LD}_{50}$ indexes (Table 4). Therefore, a toxicity scale of 1 to 10 can be constructed to better appreciate the difference between the four pollutants. Propranolol was imposed as the maximum value and the other values were normalized with the reference sample according to the following equation: 


\section{Conclusion}

Given the results obtained, it is possible to state that the Scenedesmus microalgae can act as a good bioindicator of the presence of toxic substances, coming from incorrect disposal of drugs in the aquatic environment. By comparing the values (redox potential and slope) obtained from the proposed biomonitoring with the toxicity of the drugs reported in the literature, good correlation can be evidenced.

The advantage of these microalgae is that they are of simple cultivation and easy to be handled. More they, do not require large containers for cultivation and transport and are species easy to be found in rivers and lakes, sites of great concern for drug pollution.

\section{Acknowledgements}

None.

\section{Conflicts of interest}

Author declares there are no conflicts of interest.

\section{Funding}

None.

\section{References}

1. Jujnovsky J, Almeida-Leñero L, Bojorge-García M, et al. Hydrologic ecosystem services: water quality and quantity in the Magdalena River. Hydrobiologist . 2010;20(2):113-126.

2. Daughton CG. Pharmaceuticals and the Environment (PiE): Evolution and impact of published literature revealed by bibliometric analysis. Science of the Total Environment. 2016;562:391-426.

3. Zorpas A, Dimitriou M, Voukkali I. Disposal of household pharmaceuticals in insular communities: social attitude, behavioral evaluation and prevention activities. Environmental Science and Pollution Research . 2017. p.1-11.

4. Vazquez-Roig P, Andreu V, Blasco C, et al. SPE and LC-MS / MS determination of 14 illicit drugs in the surface waters of the Albufera Natural Park (València, Spain). Analytical and Bioanalytical Chemistry. 2010;397(7):2851-2864.
5. Lübbert C, Baars C, Dayakar A, et al. Environmental pollution with antimicrobial agents from bulk drug manufacturing industries in Hyderabad, South India, is associated with the dissemination of extended-spectrum beta-lactamase and carbapenemase-producing pathogens. Infection. 2017;45(4):479-491.

6. Destrieux D, Laurent F., Budzinski H, et al. Drugs residues in urban water: A database for ecotoxicological risk management. Science of the Total Environment. 2017;609:927-941.

7. Help F, Jokela J, Castiglioni S, et al. Water-borne pharmaceuticals reduce phenotypic diversity and response capacity of natural phytoplankton communities. PLoS One. 2017;12(3):e0174207.

8. Blazer VS, Iwanowicz LR, Iwanowicz DD, et al. Intersex (testicular oocytes) in smallmouth bass from the Potomac River and selected nearby drainages. Journal of Aquatic Animal Health. 2007;19(4):242-253.

9. Pomade F, Castiglioni S, Zuccato S, et al. Effects of a Complex Mixture of Therapeutic Drugs at Environmental Levels on Human Embryonic Cells. Environmental Science \& Technology. 2006;40(7):2442-2447.

10. WHO. Worldwide country situation analysis: response to antimicrobial resistance. World Health Organization, Geneva, Swizerland. 2015.

11. Bengtsson-Palme J, Angelin M, Huss M, et al. The Human Gut Microbiome as a Transporter of Antibiotic Resistance Genes between Continents. Antimicrob Agents Chemother. 2015;59:6551-6560.

12. Reguera P, Couceiro L, Fernández N. A review of the empirical literature on the use of limpets Patella spp. (Mollusca: Gastropoda) as bioindicators of environmental quality. Ecotoxicology and Environmental Safety. 2018;148:593-600.

13. Wua N, Donga X, Liud Y, et al. Using river microalgae as indicators for freshwater biomonitoring: Review of published research and future directions. Ecological Indicators. 2017;81:124-131.

14. Jena J, Pradhan N, Nayak R, et al. Microalga Scenedesmus sp: A Potential Low-Cost Green Machine for Silver Nanoparticle Synthesis. J Microbiol Biotechnol. 2014;24(4):522-533.

15. Białk-Bielinska A, Caban M, Pieczyńska A, et al. Mixture toxicity of six sulfonamides and their two transformation products to green alga Scenedesmus vacuolatus and duckweed Lemna minor. Chemosphere. 2017;173:542-550. 